\title{
Gut Microbiota Dysbiosis in Functional Dyspepsia
}

\author{
Georgios Tziatzios ${ }^{1}$, Paraskevas Gkolfakis ${ }^{2}$, Ioannis S. Papanikolaou ${ }^{1} \mathbb{D}$, Ruchi Mathur ${ }^{3}$, \\ Mark Pimentel $^{3}$, Evangelos J. Giamarellos-Bourboulis ${ }^{4}\left(\mathbb{D}\right.$ and Konstantinos Triantafyllou ${ }^{1, *}$ (D) \\ 1 Hepatogastroenterology Unit, Second Department of Internal Medicine-Propaedeutic, Research Institute \\ and Diabetes Center, Medical School, National and Kapodistrian University of Athens, "Attikon" University \\ General Hospital, 12462 Athens, Greece; g_tziatzios@yahoo.gr (G.T.); ispapn@hotmail.com (I.S.P.) \\ 2 Department of Gastroenterology Hepatopancreatology and Digestive Oncology, Erasme University Hospital, \\ Université Libre de Bruxelles, 1070 Brussels, Belgium; pgkolfakis@med.uoa.gr \\ 3 Medically Associated Science and Technology (MAST) Program, Cedars-Sinai, Los Angeles, CA 90048, USA; \\ ruchi.mathur@cshs.org (R.M.); mark.pimentel@cshs.org (M.P.) \\ 4 4th Department of Internal Medicine, Medical School, National and Kapodistrian University of Athens, \\ 12462 Athens, Greece; egiamarel@med.uoa.gr \\ * Correspondence: ktriant@med.uoa.gr; Tel.: +30-210-583-2087; Fax: +30-210-532-6454
}

Received: 13 April 2020; Accepted: 6 May 2020; Published: 8 May 2020

\begin{abstract}
Functional dyspepsia (FD) is one of the most prevalent chronic functional gastrointestinal disorders. Several distinct pathophysiological mechanisms, including gastro duodenal motor disorders, visceral hypersensitivity, brain-gut interactions, duodenal subtle inflammation, and genetic susceptibility, have been implicated in the pathogenesis of the disease, so far. However, emerging evidence suggests that both quantitative and qualitative disturbances of the gastrointestinal microbiota may also be implicated. In this context, several studies have demonstrated differences of the commensal bacterial community between patients with FD and healthy controls, while others have shown that intestinal dysbiosis might associate with disease's symptoms severity. Elucidating these complex interactions constituting the microbiota and host crosstalk, may eventually lead to the discovery of novel, targeted therapeutic approaches that may be efficacious in treating the multiple aspects of the disorder. In this review, we summarize the data of the latest research with focus on the association between gut microbiota alterations and host regarding the pathogenesis of FD.
\end{abstract}

Keywords: microbiota; dysbiosis; functional; dyspepsia

\section{Introduction}

Functional dyspepsia (FD) is a frequent gastrointestinal (GI) disorder, characterized by epigastric pain or burning, postprandial fullness, or early satiation in the absence of structural disease on standard clinical and laboratory investigation, including upper GI endoscopy. Rome IV criteria identify three disease subtypes according to the predominant symptom pattern: postprandial distress syndrome (PDS), epigastric pain syndrome (EPS), and PDS-EPS overlap group, with variable prevalence worldwide [1]. Helicobacter pylori (H. pylori)-associated dyspepsia is now recognized as a distinct entity. The Kyoto global consensus report advocates that $H$. pylori-positive FD with a sustained response ( $>6-12$ months) to eradication therapy is referred as H. pylori-associated dyspepsia and not FD [2]. Although a subset of FD patients (10-16\%) may find symptomatic benefit after successful eradication therapy, only a minority will eventually remain asymptomatic on the long term, suggesting that $H$. pylori was not the primary cause of the dyspeptic symptoms [3,4]. Despite the latest advancements in the field, the disease's aetiology and pathophysiology remain elusive and most probably multifactorial. Gastric sensorimotor abnormalities, brain-gut axis deregulation, visceral hypersensitivity, immune activation, altered epithelial barrier permeability, psychological 
stress, genetic background, and post-infectious low-grade duodenal inflammation are listed among the complex interactions thought to give rise to FD cardinal symptoms [4-6]. Aproximately 100 trillion commensal microorganisms residue synergistically in the human gut, including bacteria, archaea, fungi, eukaryotes and viruses [7]. The largest population is that of bacteria with more than 100 different species, further classified into four major phyla: Gram-positive Firmicutes producing short-chain fatty acids, Gram-negative Bacteroidetes producing hydrogen, as well as Proteobacteria and Actionobacteria [8]. This abundant and diverse microbial ecosystem represents a key element in maintaining the homeostasis of the host, since it acts as an effective and highly specialized barrier against pathogens, interacts with the immune system and contributes to the fermentative process of dietary and endogenous substrates [9]. Accumulating evidence have highlighted the potential role of gut microbiota dysbiosis - defined as any qualitative or quantitative alteration in their composition -in the pathogenesis of gastrointestinal and extra-gastrointestinal diseases, as well [10,11]. Dysbiosis has been consistently shown to associate with the onset and progression of symptoms in patients with irritable bowel syndrome (IBS), the other principal functional gastrointestinal disorder [12]. IBS frequently develops after an episode of infectious gastroenteritis or antibiotics intake, with evidence supporting the notion that gut microbiota composition significantly varies between IBS individuals and healthy ones [12]. Similarly to IBS, intestinal dysbiosis is an evolving concept dictating its further evaluation in patients with FD $[5,13]$. Given the fact that our treatment strategy for FD remains suboptimal, a detailed understanding of the mechanisms that may relate to the development of the disorder is pivotal in the search for novel therapeutic approaches [14]. The aim of this review was to present the latest literature data concerning the potential role of gut microbiota-host crosstalk in the pathogenesis of FD.

\section{Methods and Methods}

A search in PubMed database for studies published up to March 2020 in the English language was conducted using the following key words: ("gastrointestinal microbiome"[MeSH Terms] OR ("gastrointestinal"[All Fields] AND "microbiome"[All Fields]) OR "gastrointestinal microbiome"[All Fields] OR ("gut"[All Fields] AND "microbiota"[All Fields]) OR "gut microbiota"[All Fields]) AND (functional[All Fields] AND ("dyspepsia”[MeSH Terms] OR “dyspepsia"[All Fields])).

\section{Role of Microbiota in FD Pathogenesis-Putative Pathophysiologic Mechanisms}

Evidence from animal and clinical studies imply an intriguing role for intestinal flora in FD, through a number of pathogenic mechanisms which include impaired gastrointestinal motility, visceral hypersensitivity, immune activation, increased mucosal permeability, and central nervous system disorders [10] (Figure 1).

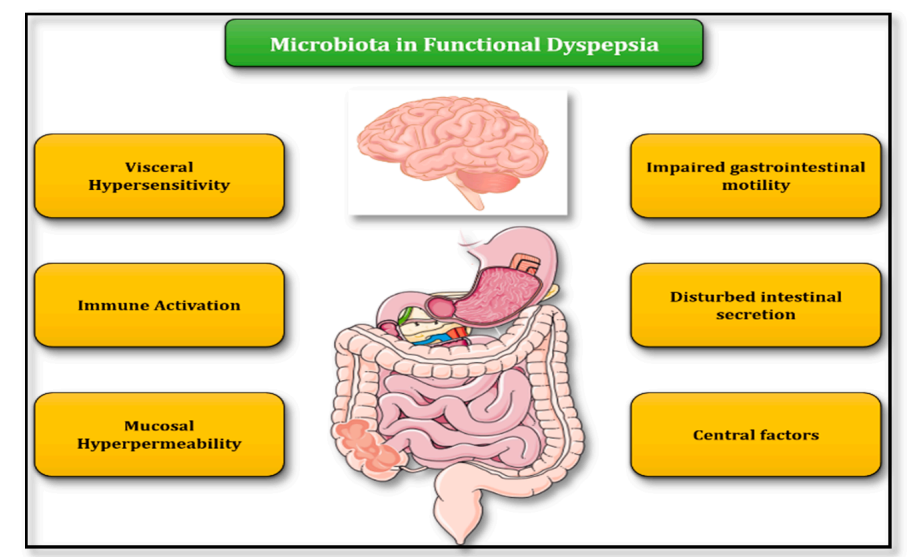

Figure 1. Putative mechanisms of gut microbiota involvement in FD pathogenesis. 


\subsection{Abnormal Gastrointestinal Motility}

Altered gastric sensorimotor function is thought to contribute to the pathophysiology of both FD and IBS [10]. Although evident, motility alterations (delayed gastric emptying, impaired gastric accommodation, hypersensitivity to distention), have been found to correlate poorly or not at all with FD symptoms [15]. Gut microbiota and gastrointestinal motility seem to be inextricably linked one to each other. On the one hand, intestinal motility disturbances can affect the number and composition of microbial commensal flora by establishing conducive intraluminal circumstances [16], while on the other hand the microbiota itself may pose certain impact on upper intestinal transit $[17,18]$. The latter can occur as a result of the prokinetic properties of various fermentative microbial products or metabolites. Among them, short chain fatty acids (SCFAs) - produced by dietary starches and carbohydrates fermentation mediated by gut bacteria-and bile acids (deconjugation and dehydroxylation of bile acids is regulated by gut bacteria) are those most well-studied, so far. More precisely, SCFAs produced by bacteria not only modulate duodenal bicarbonate secretion in FD, but at the same time their fast duodenal absorption may also influence luminal bacterial colonization suppression [19]. In addition, bacterial lipopolysaccharide produced by Escherichia coli (E. coli) has been found to induce a significant delay of gastric emptying [20], while Bifidobacterium — when used as probiotic-considerably enhances small bowel motility [21].

\subsection{Intestinal Barrier Integrity}

FD patients appear to have increased intestinal permeability of the duodenal mucosa [22]. This is thought to allow intraluminal triggers to initiate a both local and systemic immune cascade, which leads to altered neuronal signaling, generating the dyspeptic symptoms [23]. Commensal flora have a key twofold role: first, inducing intestinal barrier function maturation by promoting expression of multiple epithelial tight junction proteins (i.e., claudin-3). This was shown in an experimental study where an impaired intestinal barrier (lack of toll-like receptor adaptor protein MyD88 and claudin 3) effectively resumed its normal function after enteral administration of probiotics promoting claudin 3 expression [24]. Similarly, probiotics were also able to mediate the up-regulation of gene and protein expression of another significant element of tight junctions, namely zonula occludens 1 (ZO-1) [25]. Recent research also features the key role of zonulin - a precursor of haptoglobin-2-in maintaining the homeostasis of the intestinal mucosa. Zonulin is involved in regulation both of tight and cell-cell junctions responsible of the influx of dietary and microbial antigens via paracellular route of intestinal absorption. These data implicate zonulin as a master regulator of intestinal permeability, linked to the development of chronic inflammatory disorders [26]. Second, bacteria can even up-regulate the expression of genes involved in intestinal wall protein production; administration of probiotics resulted in altered expression levels of tight junction-related genes, including those producing occludin [27]. Research also indicates that their metabolites can also directly-without interfering neural pathways-mediate epithelium permeability, compromising intestinal barrier function [28]. It should be underlined that the abovementioned conclusions mainly derive from studies investigating the effects of probiotics on epithelial permeability; thus, may not reflect the normal situation or effect of commensals. Given the absence of studies, their results should be seen cautiously when interpreting these findings in the context of FD.

\subsection{Immune System Activation and Low-Level Inflammation}

Immune activation seen as low-grade mucosal inflammation, with duodenal mast cells and eosinophils infiltration has been described in FD [5,29]. Evidence suggest that the fundamental pathophysiologic event is a disturbance of gut-homing $\mathrm{T}$ lymphocytes population within a T-helper type 2 (Th2) or a Th17 immune response to luminal antigens, that eventually leads to disruption of the delicate mucosal homeostasis with dyspeptic symptom appearance [29]. Gut microbiota and their metabolites interfere with signaling through Toll-like Receptors (TLRs-TLR2, TLR4) and precipitate 
proinflammatory cytokines production and immune reaction [30]. Furthermore, their metabolites could also share inflammatory properties or exert direct effect on T-cell differentiation [31]. An alternative innovative disease model might be proposed for the subset of patients developing Post-infectious FD. Commonplace secondary to a bacterial gastroenteritis induced by ordinary pathogens, i.e., Campylobacter jejuni, Salmonella, E.coli, Shigella is the production of the cytolethal distending toxin (CdtB) [12]. Antibodies produced by the host against CdtB can cross-react-potentially through a molecular mimicry mechanism - with vinculin, a cytoplasmic cytoskeletal protein found in myenteric ganglia and interstitial cells of Cajal (ICC), playing a crucial part in gastrointestinal tract motility and contractility [32]. This allowed anti-CdtB and anti-vinculin circulating antibodies levels to be used as biomarkers to differentiate IBS-Diarrhea predominant type from inflammatory bowel disease (IBD) in different settings, with promising results [33]. Interestingly, higher serum titles of anti-CdtB were also observed in FD patients compared to healthy controls in a recent large Australian cohort study, indicating that a similar disease pathway might also apply for FD [34].

\subsection{Disturbances in Intestinal Secretion}

Intestinal secretion is partially regulated by molecules and metabolites (SCFAs and bile salts) produced by the bacteria flora [35]. In detail, bile acids may increase chloride secretion, while SCFAs participate in mucus, water and duodenal bicarbonate secretion $[19,36]$. Furthermore, serotonin, apart from being responsible for normal GI transit, has been also shown to contribute to visceral hypersensitivity by affecting intestinal permeability and has been associated to methane producing IBS subjects [37]. Gut microbiota may control serotonin secretion, thus featuring an alternative putative mechanism that might also implicated in FD pathogenesis [38].

\subsection{Visceral Hypersensitivity}

Although some of FD most burdensome symptoms i.e., pain, bloating, abdominal distention have been associated to excessive visceral hypersensitivity secondary to mechanical and chemical stimuli, evidence supporting the role of the bacterial community in this altered perception and sensation remain scarce $[4,39]$. Some data from experimental animal models suggest that gut microbiota might be implicated in the activity of central or peripheral neuronal pathways, while they could also produce molecules (i.e., nitric oxide, $\gamma$-aminobutyric acid) affecting sensation [40]. However, further data are needed to unveil a potential causal relationship.

\subsection{Central Nervous System Factors}

The functional link between gut and central nervous system (CNS) has been identified as an essential component of the FD pathogenesis [1]. Its disorders not only refer to an abnormal central modulation (brain to gut-activation of the hypothalamus pituitary-adrenal (HPA) axis affecting gut permeability, motility and secretion), but also involve altered intestinal signaling (gut to brain), thus, highlighting its bidirectional nature [23]. Gut microbiota fluctuations seem to relate with impaired mucosal surface integrity (through effect on TLRs and/or tight junction proteins and other inflammatory cytokines profile) [41]. The commensal bacterial community could also impress GI tract motility, once again via effect on TLR signaling, mediated by the pacemaker activity of the interstitial cells of Cajal [42]. It should be noted that bacteria produce metabolites (SCFAs) and neurotransmitters (gamma aminobutyric acid-GABA) that may also encumber brain function. Intestinal dysbiosis also causes production and release into the bloodstream of a pro-inflammatory endotoxine, lipopolysaccharide (LPS). LPS is a potent factor influencing CNS function and also leads to production of various other inflammatory cytokines that also affect physiological CNS activity, modulating neuropeptides synthesis [43]. 


\section{Helicobacter pylori (H. pylori) and Gut Microbiota}

The discovery of Helicobacter pylori (H. pylori) revolutionized our concept about gastroduodenal pathologies and more importantly gastric cancer. Beyond its undisputed carcinogenic potential in gastric epithelium that allocate the pathogen as class I carcinogen, it has been also evident that a mutual interaction between $H$. pylori and the gastric microbiota community is present $[44,45]$. One of the first studies aiming to clarify the potential differences in gastric microbiota between $H$. pylori-infected and non-infected subjects, found no difference in gastric bacterial composition at phylotype level, regardless $H$. pylori status [46]. However, this finding was not confirmed in studies that followed, where an increase in Proteobacteria and decrease in Actinobacteria, Bacteroidetes, and Firmicutes among H. pylori-positive patients was reported [47]. Another study from Mongolia using 16S rRNA gene amplicon sequencing, found that H. pylori infected subjects had significantly lower bacterial richness as well as Shannon and Simpson indices compared to those non-infected, while $H$. pylori-negative gastritis was associated with greater enrichment of Firmicutes, Fusobacteria, Bacteroidetes and Actinobacteria at phylum level [48]. An explanation for these striking discrepancies in microbiota composition could be attributed to differences of the recruited populations, in terms of dietary habits and gastric cancer risk. In this direction, a recent study detected significant differences in gastric microbiota among three distinct populations from a Southeast Asia region (the isolated Orang Asli of Malaysia, Myanmar residents and modern Malaysians), likely associated with the level of each population's modernization [49]. At length, bacterial species richness and gastric microbiota diversity was more increased among less modernized individual and could suppress H. pylori growth. On the contrary, gastric microbiota composition varied significantly among modern participants with disparate gastric diseases. Greater abundance of Cutibacterium acnes in patients with non-ulcerative dyspepsia compared to those with peptic-ulcer disease was reported, suggesting that except H. pylori this particular bacterium may also induce gastritis.

Perhaps even more interesting are the data supporting that H. pylori has the potential to alter host metabolism, while the commensal microbiota can in fact attenuate the pathogen's detrimental effect [50]. In a similar manner, $H$. pylori eradication therapy is not only able to prevent or even reverse gastric cancer development by interrupting the notorious atrophic gastritis - intestinal metaplasiacancer cascade, but has been also found to affect the host's metabolism by successfully restoring growth, weight and height along with increased serum acylated ghrelin level [51,52]. Of note, the most frequently used first-line treatment in FD, i.e., proton-pump inhibitors (PPIs) seems to cause minimal gastric microbiota alterations [53].

\section{Data from Studies Evaluating Microbiota Dysbiosis in FD}

As stated above, luminal dysbiosis may be involved in the pathogenesis of FD. Although the amount of available data supporting this is not directly comparable to that of IBS, the topic is likely to grow in importance as microbiota and imminent treatment approaches become a focal point for future research. Table 1 summarizes data from studies investigating microbiota alterations in FD [54-59].

Correlation of dysbiosis and FD was initially investigated in a prospective cohort study, comparing basic physiological properties of the gastric fluid (GF) and assessing the microbiota profile in 44 patients with FD and 44 healthy participants [54]. Authors reported significantly increased GF volume in FD patients, a finding that suggests disturbance or delayed gastric emptying. Next, using 16S rRNA gene sequencing analysis, they showed that the overall composition of the bacterial flora is different between the two groups. Moreover, the abundance of genus Prevotella and of Bifidobacterium/Clostridium was higher in FD than in healthy controls, respectively. Subsequent treatment of the FD patients with the probiotic strain of Lactobacillus gasseri OLL2716, resulted in restoration of the microbial community composition, while the abundance of Prevotella inversely correlated with the severity of PDS symptoms. In another comprehensive study using the same methodology, Igarashi and colleagues compared GF microbiota synthesis between 24 patients with FD and 21 age-matched and gender-matched healthy controls [55]. They found that bacterial composition was completely different between the two groups, 
even at the phylum level. In detail, microbiota of the FD group was characterized by increased Bacteroidetes to Proteobacteria ratio and total absence of Acidobacteria, while in the control group the ratio Bacteroidetes to Proteobacteria was decreased and Acidobacteria were present. As previously, treatment with probiotic Lactobacillus gasseri OLL2716 shifted these changes in microbiota analysis of patients with FD towards to that observed in the control group.

Table 1. Microbiota analysis studies in Functional Dyspepsia.

\begin{tabular}{|c|c|c|c|c|}
\hline Ref. & Population & $\begin{array}{l}\text { Population } \\
\text { Synthesis } \\
\text { (FD/Controls, n) }\end{array}$ & $\begin{array}{l}\text { Technique for } \\
\text { Microbiota } \\
\text { Identification }\end{array}$ & Principal Findings \\
\hline \multicolumn{5}{|c|}{ Gastric fluid aspirate } \\
\hline Nakae et al. [54] & Adult & $44 / 44$ & $\begin{array}{l}\text { 16S rRNA gene } \\
\text { sequencing }\end{array}$ & $\begin{array}{l}\text { Higher levels of Prevotella in FD, inverse } \\
\text { correlation between Prevotella abundance } \\
\text { and severity of PDS-FD }\end{array}$ \\
\hline Igarashi et al. [55] & Adult & $21 / 21$ & $\begin{array}{c}\text { 16S rRNA gene } \\
\text { sequencing }\end{array}$ & $\begin{array}{c}\text { Higher Bacteroidetes > Proteobacteria } \\
\text { abundance, absence of Acidobacteria in FD; } \\
\text { lower Bacteroidetes < Proteobacteria } \\
\text { abundance, presence of Acidobacteria } \\
\text { in controls }\end{array}$ \\
\hline \multicolumn{5}{|c|}{ Mucosa-associated microbiota (MAM) } \\
\hline Zhong et al. [56] & Adult & $9 / 9$ & $\begin{array}{l}\text { 16S rRNA gene } \\
\text { sequencing }\end{array}$ & $\begin{array}{l}\text { Streptococcus was the predominant genus } \\
\text { in both control and FD; inverse } \\
\text { relationship between abundance of } \\
\text { Streptococcus and Prevotella, Veillonella and } \\
\text { Actinomyces; negative correlation between } \\
\text { bacterial load and quality of life }\end{array}$ \\
\hline Sterbini et al. [57] & Adult & 24 & $\begin{array}{l}\text { 16S rRNA gene } \\
\text { pyrosequencing }\end{array}$ & $\begin{array}{l}\text { Higher levels of Proteobacteria, Firmicutes, } \\
\text { Bacteroidetes, Fusobacteria, and } \\
\text { Actinobacteria; higher levels of Firmicutes } \\
\text { (Streptococcaceae) and Streptococcus in } \\
\text { treatment with proton pump inhibitors }\end{array}$ \\
\hline Shanahan et al. [58] & Adult & $26 / 10$ & $\begin{array}{l}\text { 16S rRNA gene } \\
\text { sequencing }\end{array}$ & $\begin{array}{l}\text { Negative correlation between abundance } \\
\text { of Veillonella and gastric emptying time }\end{array}$ \\
\hline Fukui et al. [59] & Adult & $11 / 7$ & $\begin{array}{l}\text { 16S rRNA gene } \\
\text { sequencing }\end{array}$ & $\begin{array}{l}\text { Higher levels of Firmicutes in FD } \\
\text { compared to healthy controls; at genus } \\
\text { level, higher levels of Streptococcus in FD; } \\
\text { Streptococcus relative abundance } \\
\text { positively correlated with symptoms }\end{array}$ \\
\hline
\end{tabular}

FD: Functional Dyspepsia; C: Controls (as defined in each study).

However, these results should be seen cautiously given that microbiota populations in GF aspirations are susceptible to the effect of gastric acid, bile acids and pancreatic enzymes. More importantly, these iterations were not designed to reveal information concerning the potential region-dependent interaction of mucosa-associated microbiota (MAM) in FD [23]. To overcome these hardships, Zhong et al. [56] in a pioneer small study assessed duodenal mucosal microbiota-using a specifically designed encased biopsy forceps_-nine patients with FD and nine matched for age, sex, and body mass index controls. Streptococcus was the predominant genus in both groups, while the relative abundance of Prevotella, Veillonella and Actinomyces was significantly decreased in the FD group. Moreover, they noticed a negative correlation between duodenal mucosal bacterial load and quality of life, while as bacterial load increased, diversity decreased.

Trying to provide a detailed characterization of the gastric MAM communities in dyspeptic patients, Sterbini et al. [57] evaluated microbial populations of 24 patients using 16S rRNA gene pyrosequencing. Among patients tested negative for concurrent Helicobacter pylori infection and not receiving proton pump inhibitors, the relative abundance of Bacteroidetes and Prevotellaceae was increased, while that of Proteobacteria was decreased. Further insights into this enigmatic interplay between microbes and GI motility are provided by a study evaluating gastric and duodenal MAM in 26 consecutive FD patients and 10 controls [58]. Authors observed a significant negative correlation between the relative abundance of the genus Veillonella in duodenal but not gastric mucosa with gastric 
emptying time (Spearman's rho $(\mathrm{r})=-0.59, p<0.005)$. Correlation between FD and microbiota was also investigated in a Japanese study, where mucosa samples from five different upper gut sites (oral cavity, esophagus, gastric body, gastric antrum and duodenum) — using a brush during endoscopy—in 11 FD and seven healthy subjects were collected [59]. Although the MAM $\alpha$-diversity did not differ between the two groups, $\beta$-diversity differed, with the phylum Firmicutes being increased in FD patients across all biopsied sites. At the genus level, Streptococcus was significantly increased in FD and its relative abundance also positively correlated with symptoms severity. Finally, at a species level the relative abundance of OTU 90 (the most prevalent sequence of Streptococcus infantis) was positively correlated with PDS and EPS scores.

To summarize, intestinal dysbiosis may be associated with symptom generation or exacerbation in a subset of patients with FD through several putative mechanisms. Acknowledging the fact that current data cannot support a direct causative process that leads to development of FD, they undoubtedly show the way for future research that will lead to better comprehension of the microbiota role in FD.

\section{Modulating Microbiota as Potential Treatment for FD}

\subsection{Probiotics}

Probiotics are "live microorganisms which, when administered in adequate amounts, confer a health benefit on the host" and prebiotics as "a non-digestible food ingredient that beneficially affects the host by selectively stimulating the growth and/or the activity of one or a limited number of bacteria in the colon" [60]. In this regard, they could represent an alternative beneficial therapy for FD, targeting duodenal dysbiosis. Indeed, data from several individual studies have verified this hypothesis. In the double-blind, parallel-group, placebo-controlled, randomized, controlled trial conducted by Ohtsu and colleagues, 116 (Helicobacter pylori-negative) FD individuals were randomized to receive for a 12-week period either a daily yoghurt containing Lactobacillus gasseri OLL2716 or placebo (fermented milk product without L. gasseri) [61]. Authors observed similar impressions-assessed by a questionnaire where participants rated the severity of FD and accompanying symptoms-regarding the overall effect on gastric symptoms between the two groups $(p=0.073)$, but significantly higher elimination rates for FD symptoms in the group assigned to probiotics $(17.3 \%$ vs. $35.2 \%$ of placebo, $p=0.048)$. This finding was observed in PDS but not in EPS subjects. However, a recent meta-analysis incorporating data exclusively from five randomized controlled studies refutes the aforementioned results [62]. Although FD symptoms improved after overall treatment with probiotics or prebiotics vs. placebo (relative risk (RR): 1.15 (95\% CI: 1.01-1.30)), use of probiotics alone was not associated with significant improvement in FD symptoms (RR: 1.13; 95\% CI: 0.99-1.28). Moreover, the authors could not provide any valuable input regarding the strain or species that might be more advantageous over the others. Thus, incorporating these particular agents as therapeutic approaches seems promising but requires further confirmation.

\subsection{Antibiotics}

Antibiotics have also been extensively used in treatment of gastrointestinal diseases associated with intestinal dysbiosis (i.e., IBS) [12]. Rifaximin is a non-absorbable antibiotic with unique pharmacokinetic properties and favorable safety profile that has established itself as an efficacious option for treating diarrhea predominant IBS [63]. Although its exact mechanism of action is not entirely known, it is generally considered as multimodal, including potential anti-inflammatory actions and altering proximal small bowel microenvironment [64]. Rifaximin has been already tested in a randomized trial, where 86 consecutive FD patients were assigned to receive rifaximin $400 \mathrm{mg}$ or placebo [65]. After eight weeks, significantly more patients who had received rifaximin experienced adequate relief of both global dyspeptic symptoms (GDS) (78\% vs. 52\%), while rifaximin provided more frequently adequate relief of belching and post-prandial fullness/bloating (PPF) at week 4 . Furthermore, female sex was associated with a more favorable response to rifaximin (adequate relief of GDS at week 4: 76\% 
vs. $42 \%, p=0.006$; week $8: 79 \%$ vs. $47 \%, p=0.008$ ). Undoubtedly, these results may be an additional argument for contribution of bacteria in FD, but more data are warranted before its efficacy in treating this disorder is known.

\subsection{Fecal Microbiota Transplantation}

Fecal microbiota transplantation (FMT) has been at the spotlight during the last years, as an innovative treatment modality that could alter the natural history and outcomes in gastrointestinal diseases where gut dysbiosis is foreseen. By restoring gut microbial community with the use of healthy microbiota, FMT is an established treatment for recurrent Clostridium difficile infection (CDI), but has been lately tested also in IBS [66]. Thinking outside the box, we speculate that FMT might be a promising future enrichment of our therapeutic armamentarium for dyspeptic patients.

\section{What Lies in the Future?}

Nowadays, a growing body of evidence delineates the crucial role of gut microbiota in several physiological processes of the host, but also their implication in pathogenesis of various diseases. In order to improve our understanding regarding these mechanisms, pioneer, well-designed studies combining many different techniques (functional genomic, metagenomics, metabolomics, metatranscriptomics and metaproteomics) should be pursued. They will eventually allow the transition from simple taxonomic associations regarding abundant phyla and genera to functional phenotypes and cause-effect studies. An issue that usually remains underrated is the fact that gut microbiota represent a never-ending evolving community, subject to constant change in the form of several everyday factors, i.e., diet, body mass index, and medication (antibiotics, proton pump inhibitors), able to exert certain effect on its composition. Hence, all these individual factors as well as the significant heterogeneity in terms of study populations enrolled, criteria used to define FD, and the technique used to evaluate host-microbiota interactions represent additional challenges that should be addressed. Finally, it is imperative that future studies investigating potential therapeutic interventions (i.e., probiotics) move on from empirically administered therapies to an individualized mechanism-based diagnostic and therapeutic management model.

Author Contributions: Conceptualization, E.J.G.-B., K.T.; methodology, G.T.,P.G., I.S.P.; writing—original draft preparation, G.T., P.G., I.S.P., K.T.; writing—review and editing, G.T., P.G., I.S.P., R.M., M.P., E.J.G.-B., K.T. All authors have read and agreed to the published version of the manuscript.

Funding: This research received no external funding.

Conflicts of Interest: The authors declare no conflict of interest.

\section{References}

1. Stanghellini, V.; Chan, F.K.; Hasler, W.L.; Malagelada, J.R.; Suzuki, H.; Tack, J.; Talley, N.J. Gastroduodenal Disorders. Gastroenterology 2016, 150, 1380-1392. [CrossRef]

2. Sugano, K.; Tack, J.; Kuipers, E.J.; Graham, D.Y.; El-Omar, E.M.; Miura, S.; Haruma, K.; Asaka, M.; Uemura, N.; Malfertheiner, P.; et al. Kyoto global consensus report on Helicobacter pylori gastritis. Gut 2015, 64, 1353-1367. [CrossRef]

3. Pellicano, R.; Ribaldone, D.G.; Fagoonee, S.; Astegiano, M.; Saracco, G.M.; Megraud, F. A 2016 panorama of Helicobacter pylori infection: Key messages for clinicians. Panminerva Med. 2016, 58, 304-317.

4. Enck, P.; Azpiroz, F.; Boeckxstaens, G.; Elsenbruch, S.; Feinle-Bisset, C.; Holtmann, G.; Lackner, J.M.; Ronkainen, J.; Schemann, M.; Stengel, A.; et al. Functional dyspepsia. Nat. Rev. Dis. Primers 2017, 3, 17081. [CrossRef]

5. Talley, N.J. What Causes Functional Gastrointestinal Disorders? A Proposed Disease Model. Am. J. Gastroenterol. 2020, 115, 41-48. [CrossRef] [PubMed]

6. Kourikou, A.; Karamanolis, G.P.; Dimitriadis, G.D.; Triantafyllou, K. Gene polymorphisms associated with functional dyspepsia. World J. Gastroenterol. 2015, 21, 7672-7682. [CrossRef] [PubMed] 
7. Eckburg, P.B.; Bik, E.M.; Bernstein, C.N.; Purdom, E.; Dethlefsen, L.; Sargent, M.; Gill, S.R.; Nelson, K.E.; Relman, D.A. Diversity of the human intestinal microbial flora. Science 2005, 308, 1635-1638. [CrossRef] [PubMed]

8. Backhed, F.; Ley, R.E.; Sonnenburg, J.L.; Peterson, D.A.; Gordon, J.I. Host-bacterial mutualism in the human intestine. Science 2005, 307, 1915-1920. [CrossRef]

9. Lynch, S.V.; Pedersen, O. The Human Intestinal Microbiome in Health and Disease. N. Engl. J. Med. 2016, 375, 2369-2379. [CrossRef]

10. Barbara, G.; Feinle-Bisset, C.; Ghoshal, U.C.; Quigley, E.M.; Santos, J.; Vanner, S.; Vergnolle, N.; Zoetendal, E.G. The Intestinal Microenvironment and Functional Gastrointestinal Disorders. Gastroenterology 2016, 150, 1305-1318. [CrossRef]

11. Gkolfakis, P.; Dimitriadis, G.; Triantafyllou, K. Gut microbiota and non-alcoholic fatty liver disease. Hepatobiliary Pancreat. Dis. Int. 2015, 14, 572-581. [CrossRef]

12. Pimentel, M.; Lembo, A. Microbiome and Its Role in Irritable Bowel Syndrome. Dig. Dis. Sci. 2020, 65, 829-839. [CrossRef] [PubMed]

13. Tziatzios, G.; Giamarellos-Bourboulis, E.J.; Papanikolaou, I.S.; Pimentel, M.; Dimitriadis, G.D.; Triantafyllou, K. Is small intestinal bacterial overgrowth involved in the pathogenesis of functional dyspepsia? Med. Hypotheses 2017, 106, 26-32. [CrossRef] [PubMed]

14. Eusebi, L.H.; Black, C.J.; Howden, C.W.; Ford, A.C. Effectiveness of management strategies for uninvestigated dyspepsia: Systematic review and network meta-analysis. BMJ 2019, 367, 16483. [CrossRef]

15. Vanheel, H.; Carbone, F.; Valvekens, L.; Simren, M.; Tornblom, H.; Vanuytsel, T.; Van Oudenhove, L.; Tack, J. Pathophysiological Abnormalities in Functional Dyspepsia Subgroups According to the Rome III Criteria. Am. J. Gastroenterol. 2017, 112, 132-140. [CrossRef]

16. Reigstad, C.S.; Kashyap, P.C. Beyond phylotyping: Understanding the impact of gut microbiota on host biology. NeuroGastroenterol. Motil. 2013, 25, 358-372. [CrossRef]

17. De Palma, G.; Lynch, M.D.; Lu, J.; Dang, V.T.; Deng, Y.; Jury, J.; Umeh, G.; Miranda, P.M.; Pigrau Pastor, M.; Sidani, S.; et al. Transplantation of fecal microbiota from patients with irritable bowel syndrome alters gut function and behavior in recipient mice. Sci. Transl. Med. 2017, 9. [CrossRef]

18. Husebye, E.; Hellstrom, P.M.; Sundler, F.; Chen, J.; Midtvedt, T. Influence of microbial species on small intestinal myoelectric activity and transit in germ-free rats. Am. J. Physiol. Gastrointest Liver Physiol. 2001, 280, G368-G380. [CrossRef]

19. Kaji, I.; Iwanaga, T.; Watanabe, M.; Guth, P.H.; Engel, E.; Kaunitz, J.D.; Akiba, Y. SCFA transport in rat duodenum. Am. J. Physiol. Gastrointest Liver Physiol. 2015, 308, G188-G197. [CrossRef]

20. Collares, E.F. Effect of bacterial lipopolysaccharide on gastric emptying of liquids in rats. Braz. J. Med. Biol. Res. 1997, 30, 207-211. [CrossRef]

21. Agrawal, A.; Houghton, L.A.; Morris, J.; Reilly, B.; Guyonnet, D.; Goupil Feuillerat, N.; Schlumberger, A.; Jakob, S.; Whorwell, P.J. Clinical trial: The effects of a fermented milk product containing Bifidobacterium lactis DN-173 010 on abdominal distension and gastrointestinal transit in irritable bowel syndrome with constipation. Aliment. Pharmacol. Ther. 2009, 29, 104-114. [CrossRef] [PubMed]

22. Vanheel, H.; Vicario, M.; Vanuytsel, T.; Van Oudenhove, L.; Martinez, C.; Keita, A.V.; Pardon, N.; Santos, J.; Soderholm, J.D.; Tack, J.; et al. Impaired duodenal mucosal integrity and low-grade inflammation in functional dyspepsia. Gut 2014, 63, 262-271. [CrossRef] [PubMed]

23. Wauters, L.; Talley, N.J.; Walker, M.M.; Tack, J.; Vanuytsel, T. Novel concepts in the pathophysiology and treatment of functional dyspepsia. Gut 2020, 69, 591-600. [CrossRef] [PubMed]

24. Patel, R.M.; Myers, L.S.; Kurundkar, A.R.; Maheshwari, A.; Nusrat, A.; Lin, P.W. Probiotic bacteria induce maturation of intestinal claudin 3 expression and barrier function. Am. J. Pathol. 2012, 180, 626-635. [CrossRef]

25. Ukena, S.N.; Singh, A.; Dringenberg, U.; Engelhardt, R.; Seidler, U.; Hansen, W.; Bleich, A.; Bruder, D.; Franzke, A.; Rogler, G.; et al. Probiotic Escherichia coli Nissle 1917 inhibits leaky gut by enhancing mucosal integrity. PLoS ONE 2007, 2, e1308. [CrossRef]

26. Caviglia, G.P.; Rosso, C.; Ribaldone, D.G.; Dughera, F.; Fagoonee, S.; Astegiano, M.; Pellicano, R. Physiopathology of intestinal barrier and the role of zonulin. Minerva Biotecnol. 2019, 31, 83-92. [CrossRef] 
27. Anderson, R.C.; Cookson, A.L.; McNabb, W.C.; Park, Z.; McCann, M.J.; Kelly, W.J.; Roy, N.C. Lactobacillus plantarum MB452 enhances the function of the intestinal barrier by increasing the expression levels of genes involved in tight junction formation. BMC MicroBiol. 2010, 10, 316. [CrossRef]

28. Forsgard, R.A.; Korpela, R.; Stenman, L.K.; Osterlund, P.; Holma, R. Deoxycholic acid induced changes in electrophysiological parameters and macromolecular permeability in murine small intestine with and without functional enteric nervous system plexuses. NeuroGastroenterol. Motil. 2014, 26, 1179-1187. [CrossRef]

29. Burns, G.; Carroll, G.; Mathe, A.; Horvat, J.; Foster, P.; Walker, M.M.; Talley, N.J.; Keely, S. Evidence for Local and Systemic Immune Activation in Functional Dyspepsia and the Irritable Bowel Syndrome: A Systematic Review. Am. J. Gastroenterol. 2019, 114, 429-436. [CrossRef]

30. Anitha, M.; Vijay-Kumar, M.; Sitaraman, S.V.; Gewirtz, A.T.; Srinivasan, S. Gut microbial products regulate murine gastrointestinal motility via Toll-like receptor 4 signaling. Gastroenterology 2012, 143, 1006-1016. [CrossRef]

31. Powell, N.; Walker, M.M.; Talley, N.J. The mucosal immune system: Master regulator of bidirectional gut-brain communications. Nat. Rev. Gastroenterol. Hepatol. 2017, 14, 143-159. [CrossRef] [PubMed]

32. Pimentel, M.; Morales, W.; Pokkunuri, V.; Brikos, C.; Kim, S.M.; Kim, S.E.; Triantafyllou, K.; Weitsman, S.; Marsh, Z.; Marsh, E.; et al. Autoimmunity Links Vinculin to the Pathophysiology of Chronic Functional Bowel Changes Following Campylobacter jejuni Infection in a Rat Model. Dig. Dis. Sci. 2015, 60, 1195-1205. [CrossRef] [PubMed]

33. Chira, A.; Dumitrascu, D.L. Serum biomarkers for irritable bowel syndrome. Clujul Med. 2015, 88, $258-264$. [CrossRef] [PubMed]

34. Talley, N.J.; Holtmann, G.; Walker, M.M.; Burns, G.; Potter, M.; Shah, A.; Jones, M.; Koloski, N.A.; Keely, S. Circulating Anti-cytolethal Distending Toxin B and Anti-vinculin Antibodies as Biomarkers in Community and Healthcare Populations With Functional Dyspepsia and Irritable Bowel Syndrome. Clin. Transl. Gastroenterol. 2019, 10, e00064. [CrossRef] [PubMed]

35. Camilleri, M. Peripheral mechanisms in irritable bowel syndrome. N. Engl. J. Med. 2012, 367, $1626-1635$. [CrossRef] [PubMed]

36. Jones, M.L.; Tomaro-Duchesneau, C.; Prakash, S. The gut microbiome, probiotics, bile acids axis, and human health. Trends MicroBiol. 2014, 22, 306-308. [CrossRef]

37. Pimentel, M.; Kong, Y.; Park, S. IBS Subjects with Methane on Lactulose Breath Test Have Lower Postprandial Serotonin Levels Than Subjects with Hydrogen. Dig. Dis. Sci. 2004, 49, 84-87. [CrossRef]

38. Yano, J.M.; Yu, K.; Donaldson, G.P.; Shastri, G.G.; Ann, P.; Ma, L.; Nagler, C.R.; Ismagilov, R.F.; Mazmanian, S.K.; Hsiao, E.Y. Indigenous bacteria from the gut microbiota regulate host serotonin biosynthesis. Cell 2015, 161, 264-276. [CrossRef]

39. Simren, M.; Tornblom, H.; Palsson, O.S.; van Tilburg, M.A.L.; Van Oudenhove, L.; Tack, J.; Whitehead, W.E. Visceral hypersensitivity is associated with GI symptom severity in functional GI disorders: Consistent findings from five different patient cohorts. Gut 2018, 67, 255-262. [CrossRef]

40. Burri, E.; Barba, E.; Huaman, J.W.; Cisternas, D.; Accarino, A.; Soldevilla, A.; Malagelada, J.R.; Azpiroz, F. Mechanisms of postprandial abdominal bloating and distension in functional dyspepsia. Gut 2014, 63, 395-400. [CrossRef]

41. McKernan, D.P.; Gaszner, G.; Quigley, E.M.; Cryan, J.F.; Dinan, T.G. Altered peripheral toll-like receptor responses in the irritable bowel syndrome. Aliment. Pharmacol. Ther. 2011, 33, 1045-1052. [CrossRef] [PubMed]

42. Mikkelsen, H.B. Interstitial cells of Cajal, macrophages and mast cells in the gut musculature: Morphology, distribution, spatial and possible functional interactions. J. Cell Mol. Med. 2010, 14, 818-832. [CrossRef]

43. Cryan, J.F.; Dinan, T.G. Mind-altering microorganisms: The impact of the gut microbiota on brain and behaviour. Nat. Rev. NeuroSci. 2012, 13, 701-712. [CrossRef]

44. Triantafyllou, K.; Papadopoulos, V.; Emanouil, T.; Gkolfakis, P.; Damaskou, V.; Tziatzios, G.; Panayiotides, I.G.; Vafiadis, I.; Ladas, S.D. Eradication of Helicobacter pylori Infection Restores ki67, p53, and Cyclin D1 Immunoreactivity in the Human Gastric Epithelium. Clin. Med. Insights Gastroenterol. 2016, 9, 73-78. [CrossRef] [PubMed]

45. Schütte, K.; Malfertheiner, P.; Schulz, C. What is the Relevance of Gastric Microbiota Beyond H. pylori? Curr. Treat. Options Gastroenterol. 2019, 17, 619-627. [CrossRef] 
46. Bik, E.M.; Eckburg, P.B.; Gill, S.R.; Nelson, K.E.; Purdom, E.A.; Francois, F.; Perez-Perez, G.; Blaser, M.J.; Relman, D.A. Molecular analysis of the bacterial microbiota in the human stomach. Proc. Natl. Acad. Sci. USA 2006, 103, 732-737. [CrossRef] [PubMed]

47. Maldonado-Contreras, A.; Goldfarb, K.C.; Godoy-Vitorino, F.; Karaoz, U.; Contreras, M.; Blaser, M.J.; Brodie, E.L.; Dominguez-Bello, M.G. Structure of the human gastric bacterial community in relation to Helicobacter pylori status. ISME J. 2011, 5, 574-579. [CrossRef]

48. Gantuya, B.; El-Serag, H.B.; Matsumoto, T.; Ajami, N.J.; Oyuntsetseg, K.; Azzaya, D.; Uchida, T.; Yamaoka, Y. Gastric Microbiota in Helicobacter pylori-Negative and -Positive Gastritis Among High Incidence of Gastric Cancer Area. Cancers 2019, 11, 504. [CrossRef]

49. Chua, E.G.; Loke, M.F.; Gunaletchumy, S.P.; Gan, H.M.; Thevakumar, K.; Tay, C.Y.; Young, S.; Aye, T.T.; Maw, W.W.; Aye, M.M.; et al. The Influence of Modernization and Disease on the Gastric Microbiome of Orang Asli, Myanmars and Modern Malaysians. Microorganisms 2019, 7, 174. [CrossRef]

50. Yang, Y.J.; Sheu, B.S. Metabolic Interaction of Helicobacter pylori Infection and Gut Microbiota. Microorganisms 2016, 4, 15. [CrossRef]

51. Rokkas, T.; Rokka, A.; Portincasa, P. A systematic review and meta-analysis of the role of Helicobacter pylori eradication in preventing gastric cancer. Ann. Gastroenterol. 2017, 30, 414-423. [CrossRef]

52. Yang, Y.J.; Sheu, B.S.; Yang, H.B.; Lu, C.C.; Chuang, C.C. Eradication of Helicobacter pylori increases childhood growth and serum acylated ghrelin levels. World J. Gastroenterol. 2012, 18, 2674-2681. [CrossRef] [PubMed]

53. Parsons, B.N.; Ijaz, U.Z.; D’Amore, R.; Burkitt, M.D.; Eccles, R.; Lenzi, L.; Duckworth, C.A.; Moore, A.R.; Tiszlavicz, L.; Varro, A.; et al. Comparison of the human gastric microbiota in hypochlorhydric states arising as a result of Helicobacter pylori-induced atrophic gastritis, autoimmune atrophic gastritis and proton pump inhibitor use. PLoS Pathog. 2017, 13, e1006653. [CrossRef] [PubMed]

54. Nakae, H.; Tsuda, A.; Matsuoka, T.; Mine, T.; Koga, Y. Gastric microbiota in the functional dyspepsia patients treated with probiotic yogurt. BMJ Open Gastroenterol. 2016, 3, e000109. [CrossRef]

55. Igarashi, M.; Nakae, H.; Matsuoka, T.; Takahashi, S.; Hisada, T.; Tomita, J.; Koga, Y. Alteration in the gastric microbiota and its restoration by probiotics in patients with functional dyspepsia. BMJ Open Gastroenterol. 2017, 4, e000144. [CrossRef] [PubMed]

56. Zhong, L.; Shanahan, E.R.; Raj, A.; Koloski, N.A.; Fletcher, L.; Morrison, M.; Walker, M.M.; Talley, N.J.; Holtmann, G. Dyspepsia and the microbiome: Time to focus on the small intestine. Gut 2017, 66, 1168-1169. [CrossRef]

57. Paroni Sterbini, F.; Palladini, A.; Masucci, L.; Cannistraci, C.V.; Pastorino, R.; Ianiro, G.; Bugli, F.; Martini, C.; Ricciardi, W.; Gasbarrini, A.; et al. Effects of Proton Pump Inhibitors on the Gastric Mucosa-Associated Microbiota in Dyspeptic Patients. Appl. Environ. MicroBiol. 2016, 82, 6633-6644. [CrossRef]

58. Shanahan, E.R.; Shah, A.; Do, A.; Fairlie, T.; Ghasemi, P.; Hansen, T.J.; Koloski, N.A.; Keely, S.; Walker, M.M.; Talley, N.J.; et al. 146 - Duodenal Mucosa-Associated Microbiota (MAM) and Gastric Emptying: Veillonella in the Duodenal MAM Linked to slow Gastric Emptying. Gastroenterology 2018, 154, S40. [CrossRef]

59. Fukui, A.; Takagi, T.; Naito, Y.; Inoue, R.; Kashiwagi, S.; Mizushima, K.; Inada, Y.; Inoue, K.; Harusato, A.; Dohi, O.; et al. Higher Levels of Streptococcus in Upper Gastrointestinal Mucosa Associated with Symptoms in Patients with Functional Dyspepsia. Digestion 2020, 101, 38-45. [CrossRef]

60. Wu, R.Y.; Maattanen, P.; Napper, S.; Scruten, E.; Li, B.; Koike, Y.; Johnson-Henry, K.C.; Pierro, A.; Rossi, L.; Botts, S.R.; et al. Non-digestible oligosaccharides directly regulate host kinome to modulate host inflammatory responses without alterations in the gut microbiota. Microbiome 2017, 5, 135. [CrossRef]

61. Ohtsu, T.; Takagi, A.; Uemura, N.; Inoue, K.; Sekino, H.; Kawashima, A.; Uchida, M.; Koga, Y. The Ameliorating Effect of Lactobacillus gasseri OLL2716 on Functional Dyspepsia in Helicobacter pylori-Uninfected Individuals: A Randomized Controlled Study. Digestion 2017, 96, 92-102. [CrossRef] [PubMed]

62. Zhang, J.; Wu, H.M.; Wang, X.; Xie, J.; Li, X.; Ma, J.; Wang, F.; Tang, X. Efficacy of prebiotics and probiotics for functional dyspepsia: A systematic review and meta-analysis. Medicine 2020, 99, e19107. [CrossRef] [PubMed]

63. Pimentel, M.; Lembo, A.; Chey, W.D.; Zakko, S.; Ringel, Y.; Yu, J.; Mareya, S.M.; Shaw, A.L.; Bortey, E.; Forbes, W.P.; et al. Rifaximin therapy for patients with irritable bowel syndrome without constipation. N. Engl. J. Med. 2011, 364, 22-32. [CrossRef] 
64. Triantafyllou, K.; Sioulas, A.D.; Giamarellos-Bourboulis, E.J. Rifaximin: The Revolutionary Antibiotic Approach for Irritable Bowel Syndrome. Mini Rev. Med. Chem. 2015, 16, 186-192. [CrossRef] [PubMed]

65. Tan, V.P.; Liu, K.S.; Lam, F.Y.; Hung, I.F.; Yuen, M.F.; Leung, W.K. Randomised clinical trial: Rifaximin versus placebo for the treatment of functional dyspepsia. Aliment. Pharmacol. Ther. 2017, 45, 767-776. [CrossRef] [PubMed]

66. Johnsen, P.H.; Hilpusch, F.; Cavanagh, J.P.; Leikanger, I.S.; Kolstad, C.; Valle, P.C.; Goll, R. Faecal microbiota transplantation versus placebo for moderate-to-severe irritable bowel syndrome: A double-blind, randomised, placebo-controlled, parallel-group, single-centre trial. Lancet Gastroenterol. Hepatol. 2018, 3, 17-24. [CrossRef]

(C) 2020 by the authors. Licensee MDPI, Basel, Switzerland. This article is an open access article distributed under the terms and conditions of the Creative Commons Attribution (CC BY) license (http://creativecommons.org/licenses/by/4.0/). 